\title{
Measurements of Ionic Liquids Thermal Conductivity and Thermal Diffusivity
}

Yansong Zhao ${ }^{\text {a,* }}$, Yingpeng Zhen ${ }^{\mathrm{b}}$, Bjørn Petter Jelle ${ }^{\mathrm{b}, \mathrm{c}}$, and Tobias Boström ${ }^{\mathrm{a}}$

${ }^{a}$ Energy and Climate Group, Department of Physics and Technology, UiT The Arctic University of Norway, NO-9037 Tromsø, Norway.

${ }^{\mathrm{b}}$ Department of Civil and Transport Engineering, Norwegian University of Science and Technology (NTNU), NO-7491 Trondheim, Norway.

${ }^{\mathrm{c}}$ Department of Materials and Structures, SINTEF Building and Infrastructure, NO-7465 Trondheim, Norway.

\section{Abstract}

Thermal conductivity and thermal diffusivity of ionic liquids (ILs) are investigated in this work. A hot disk method for ILs thermal conductivity and thermal diffusivity measurement is utilized. Firstly, the thermal conductivity of water is measured to check the reliability of the hot disk method. In addition, the thermal conductivity of pure ILs, including $\mathrm{BmimBF}_{4}, \mathrm{BmimPF}_{6}, \mathrm{OmimCl}_{1} \mathrm{BmimFeCl}_{4}$, and $\mathrm{OmimFeCl}_{4}$, is measured. By comparison with thermal conductivity values of water, $\mathrm{BmimBF}_{4}$, and $\mathrm{BmimPF}_{6}$ in the literatures, it is found that the thermal conductivity values of ILs using hot disk method has high reliability. Therefore, the hot disk method is utilized for thermal conductivity measurement of ILs in this work. The experimental results also show that all the average thermal conductivity values of the 5 pure ILs are no more than $0.1898 \mathrm{Wm}^{-1} \mathrm{~K}^{-1}$, which is much lower than the average measured thermal conductivity of water, namely $0.6033 \mathrm{Wm}^{-1} \mathrm{~K}^{-1}$. Effect of nanoparticles (NPs) on thermal conductivity of ILs is also investigated. It is shown that the thermal conductivity of $\mathrm{BmimBF}_{4}$ does not change significantly in the presence of $\mathrm{Fe}_{2} \mathrm{O}_{3}$ NPs. However, the thermal conductivity of $\mathrm{BmimPF}_{6}$ decreases somewhat in the presence of R711 NPs. In addition, the thermal diffusivity of pure ILs, including $\mathrm{BmimBF}_{4}, \mathrm{BmimPF}_{6}, \mathrm{BmimFeCl}_{4}$, OmimCl and $\mathrm{OmimFeCl}_{4}$, is measured. All the average thermal diffusivity values of the ILs of $\mathrm{BmimBF}_{4}$, $\mathrm{BmimPF}_{6}, \mathrm{BmimFeCl}_{4}, \mathrm{OmimCl}$ and $\mathrm{OmimFeCl}_{4}$, are no more than $0.1185 \mathrm{~mm}^{2} \mathrm{~s}^{-1}$. The thermal

${ }^{*}$ Corresponding author. Yansong Zhao

Address: Energy and Climate Group, Department of Physics and Technology, UiT The Arctic University of Norway, NO-9037 Tromsø, Norway.

E-mails: yansong.zhao2004@gmail.com; yansong.zhao@uit.no. 
diffusivity of water is $0.143 \mathrm{~mm}^{2} \mathrm{~s}^{-1}$ in the literature. It illustrates that the ILs also have a better thermal property than water for energy storage. ILs may be utilized as novel materials for energy storage. Effect of NPs on thermal diffusivity of ILs is also investigated. The results are similar to how NPs influence thermal conductivity of $\mathrm{BmimBF}_{4}$ and $\mathrm{BmimPF}_{6}$. In the presence of $\mathrm{Fe}_{2} \mathrm{O}_{3} \mathrm{NPs}$, thermal diffusivity of $\mathrm{BmimBF}_{4}$ does not change significantly. However, in the presence of R711 NPs, thermal diffusivity of $\mathrm{BmimPF}_{6}$ decreases somewhat.

Keywords: Ionic liquid, nanoparticle, thermal conductivity, thermal diffusivity, thermal property, hot disk.

\section{Introduction}

Ionic liquids (ILs) are environmentally friendly materials. ILs have many excellent properties, which currently are hot research topics. Due to the excellent properties, ILs have been utilized as novel and promising materials in many research fields. For example, ILs can be utilized in energy conversion and energy storage, including solar cells [1-7], batteries [8-16], and supercapacitors [17-28].

Thermal properties of ILs are important.[29-31] Thermal conductivity is the ability of a material to conduct heat, which is an important parameter for utilization of ILs [32-34]. Thermal conductivity and thermal diffusivity are crucial for application of ILs in real energy conversion and energy storage processes. However, there is scant literature that can be found for thermal conductivity measurement of ILs. Frez et al. utilized the transient grating method for the thermal conductivity measurement of 7 ILs [35]. In the work of Ge et al., the transient hot-wire method was utilized to measure the thermal conductivity of 11 pure ILs [36]. Fröba et al. measured the thermal conductivity of ILs using parallelplate method [37]. The thermal conductivity data of ILs are limited in the current literatures. Therefore, the thermal conductivity of ILs is measured using a hot disk method in this work. In addition, the effect of nanoparticles (NPs) on the thermal conductivity of ILs is investigated.

Thermal diffusivity is the ability of a material to conduct thermal energy relative to its ability to store thermal energy [38]. The definition of thermal diffusivity $\alpha$ is as follows:

$$
\alpha=\frac{\kappa}{\rho c_{p}}
$$

where $\alpha, \kappa, \rho$, and $c_{p}$ are thermal diffusivity, thermal conductivity, mass density, and specific heat capacity, respectively. Thermal diffusivity is also an important parameter for utilization of ILs. However, the thermal diffusivity measurement of ILs is extremely scant. Frez et al. [35] are the only researchers who experimentally measured the thermal diffusivity of pure ILs according to our own knowledge. In the 
work of Frez et al., transient grating technique was utilized for measurement of pure ILs thermal diffusivity [35]. We found the thermal diffusivity data of ILs are rarely known in the current literatures. Therefore, in this work the thermal diffusivity of ILs is measured using hot disk method. In addition, the effect of NPs on thermal diffusivity of ILs is investigated.

\section{Theory}

The theory of hot disk method is introduced in this part based on the Introduction Manual of Hot Disk Thermal Constants Analyser [39]. The hot disk is electrically heated for the thermal conductivity and thermal diffusivity measurement. The resistance increase can be described as a function of time as follows:

$$
R(t)=R_{0}\left\{1+\beta\left[\Delta T_{i}+\Delta T_{a}(\tau)\right]\right\}
$$

where $R(t)$ is disk resistance at time $\mathrm{t}, R_{0}$ is disk resistance at time $\mathrm{t}=0, \beta$ is temperature coefficient of resistivity, $\Delta T_{i}$ is the constant temperature difference, and $\Delta T_{a}(\tau)$ is time dependent temperature increase [39]. The time dependent temperature increase can be obtained by the theory as follows:

$$
\Delta T_{a}(\tau)=\frac{P_{0}}{\pi^{3 / 2} \cdot a \cdot \kappa} \cdot D(\tau)
$$

where $P_{0}$ is the total power output of the sensor, $a$ is the overall radius of the disk, $\kappa$ is the testing thermal conductivity of the sample, and $D(\tau)$ is a dimensionless time dependent function, [39]

where $\tau$ is given by the following:

$\tau=\sqrt{\frac{t}{\Theta}}$

where $t$ is the time measured from the start of the transient recording, and $\Theta$ is the characteristic time which can be defined as follows: [39]

$\Theta=\frac{\alpha^{2}}{\kappa}$

During the experiment process, the experimental curve of temperature increase versus elapsed time can be obtained. Subsequently, the curve of temperature increase versus $D(\tau)$ can be obtained by calculation. Then the curve of temperature increase versus $D(\tau)$ can be fitted using a linear line. The slope of the linear fitting line can be obtained. As is shown in Equation 3, the slope of the linear fitting line is $\frac{P_{0}}{\pi^{3 / 2} \cdot a \cdot \kappa}$. As known, in the experiments of this work, the total power $P_{0}$ is $0.02 \mathrm{~W}$, and the overall radius 
of the disk $a$ is $3.189 \mathrm{~mm}$. Therefore, the thermal conductivity $\kappa$ can be calculated [39]. In addition, after the value of thermal conductivity, the value of thermal diffusivity can be calculated based on Equations $3-5$.

\section{Experimental Section}

Materials. ILs of 1-butyl-3-methylimidazolium tetrafluoroborate (CAS R.N. 174501-65-6, BmimBF4), 1-butyl-3-methylimidazolium hexafluorophosphate (CAS R.N. 174501-64-5, BmimPF6), and 1-methyl3-octylimidazolium chloride (CAS R.N. 64697-40-1, OmimCl), are obtained from Sigma-Aldrich. The mass fractions purity of the $3 \mathrm{ILs}$ are $\geqslant 97 \%$. $\mathrm{Fe}_{2} \mathrm{O}_{3}$ nanoparticles (NPs) (Average size: $<50 \mathrm{~nm}$ ) are also purchased from Sigma-Aldrich and utilized in this work. R711 NPs are received from Evonik Industries AG, Germany. ILs of $\mathrm{BmimFeCl}_{4}$ and $\mathrm{OmimFeCl}_{4}$ are synthesized in our laboratory and utilized in this work. The synthesis procedure of $\mathrm{BmimFeCl}_{4}$ can be found from our previous work [40]. The chemical structures of the ILs utilized in this work are shown in Scheme 1. Samples of BmimPF $6+$ R711 NPs and $\mathrm{BmimBF}_{4}+\mathrm{Fe}_{2} \mathrm{O}_{3}$ NPs are also prepared in this work. The two samples are treated using ultrasound instrument at $30{ }^{\circ} \mathrm{C}$ for at least 30 minutes before the measurement. The ultrasound can enhance the NPs dispersed in the ILs. It is found the dispersed ability of R711 NPs in BmimPF 6 is excellent. However, the dispersed ability of $\mathrm{Fe}_{2} \mathrm{O}_{3}$ NPs is not as good as the former one. The $\mathrm{Fe}_{2} \mathrm{O}_{3} \mathrm{NPs}$ can be precipitated from the bulk $\mathrm{BmimBF}_{4}$ after a long time quiescent process.

Thermal Conductivity Measurements. Thermal conductivity of ILs is measured using hot disk method. The experimental procedure is given as follows. The hot disk instrument should be turned on at least 1 hour before the thermal conductivity measurement experiments are performed. A sample is added into a beaker. Subsequently, the sensor is put into the sample. There should be sample material at least 25 $\mathrm{mm}$ around the senor. The total power and measurement time for the given experiments are $0.02 \mathrm{~W}$ and $5 \mathrm{~s}$, respectively. The experimental data of the temperature increase versus elapsed time are recorded during the process. Finally, the thermal conductivity of the sample can be calculated based on Equations $3-5$.

Thermal Diffusivity Measurements. Thermal diffusivity of ILs is also measured using hot disk method. The thermal diffusivity measurement procedure is the same as the experimental procedure for thermal conductivity measurement. The thermal diffusivity can be calculated based on the experimental data and Equations 3-5. Hot disk method is a new method for ILs thermal diffusivity measurement.

\section{Results and Discussions}

Thermal Conductivity and Thermal Diffusivity Measurements of ILs using Hot Disk Method 
The thermal conductivity and thermal diffusivity measurement process using the hot disk method is shown as follows. In order to demonstrate the procedure, the method on determination of the thermal conductivity and thermal diffusivity of $\mathrm{BmimBF}_{6}$ is shown as an example. The experiments for thermal conductivity and thermal diffusivity measurement of $\mathrm{BmimBF}_{6}$ are repeated for three times. As shown in Fig. 1a, the experimental curve of temperature increase versus elapsed time can be obtained directly during the process. Subsequently, the curve of temperature increase versus $\mathrm{D}(\tau)$ can be calculated and obtained, which is shown in Fig. 1b. In addition, the curve of temperature increase versus $\mathrm{D}(\tau)$ can be fitted using a linear line. The linear line fitting results are also shown in Fig. 1b. The slope of the linear fitting line can be obtained. Based on Equations 3-5, the thermal conductivity and thermal diffusivity of $\mathrm{BmimPF}_{6}$ can be calculated. Moreover, the experimental data of difference temperature versus square root of time is obtained and shown in Fig. 1c. Furthermore, the experimental data of temperature drift versus time can be obtained during the process and is shown for BmimPF 6 in Fig. 1d. This curve can be utilized to check the temperature drift during the process, which is important as to whether the experimental data is reliable or not.

\section{Thermal Conductivity Measurements}

Reliability of Hot Disk Method. The thermal conductivity of water is measured using the hot disk method at $21{ }^{\circ} \mathrm{C}$. The experimental results are shown in Table 1. The average measured thermal conductivity value of water is $0.6033 \mathrm{Wm}^{-1} \mathrm{~K}^{-1}$ at $21^{\circ} \mathrm{C}$ in this work. The reference thermal conductivity value of water at $20{ }^{\circ} \mathrm{C}$ is $0.6 \mathrm{Wm}^{-1} \mathrm{~K}^{-1}$ [34]. In addition, the measured thermal conductivity values of pure ILs $\mathrm{BmimBF}_{4}$ and $\mathrm{BmimPF}_{6}$ are $0.1898 \mathrm{Wm}^{-1} \mathrm{~K}^{-1}$ and $0.1733 \mathrm{Wm}^{-1} \mathrm{~K}^{-1}$ at $21{ }^{\circ} \mathrm{C}$, respectively. The reference values of thermal conductivity of $\mathrm{BmimBF}_{4}$ and $\mathrm{BmimPF}_{6}$ are $0.186 \mathrm{Wm}^{-1} \mathrm{~K}^{-1}$ and $0.145 \mathrm{Wm}^{-}$ ${ }^{1} \mathrm{~K}^{-1}$ at $25^{\circ} \mathrm{C}$, respectively [41]. The measurement results are in good agreements with the reference values. Therefore, the hot disk method are utilized to measure the thermal conductivity of ILs based materials in this work.

Pure ILs Thermal Conductivity Measurements. Thermal conductivity of pure ILs, including $\mathrm{BmimBF}_{4}, \mathrm{BmimPF}_{6}, \mathrm{OmimCl}_{\mathrm{BmimFeCl}}$, and $\mathrm{OmimFeCl}_{4}$, is measured at $21{ }^{\circ} \mathrm{C}$. The curve of temperature increase versus elapsed time of $\mathrm{BmimPF}_{6}$ is shown in Fig. 1a. The curves of temperature increase versus time of the other 4 ILs are shown in Fig. 2. Based on the temperature increase versus time curves, the temperature increase versus $\mathrm{D}(\tau)$ curves of the ILs can be obtained, which are shown in Fig. $1 \mathrm{~b}$ and Fig. 3. Subsequently, based on Equations 3-5, the thermal conductivity of ILs can be calculated. The results are shown in Table 2. It is found that the measurement thermal conductivity values of the 5 pure ILs are no more than $0.1898 \mathrm{Wm}^{-1} \mathrm{~K}^{-1}$. However, the measurement thermal conductivity value of 
water is $0.6033 \mathrm{Wm}^{-1} \mathrm{~K}^{-1}$. The thermal conductivity of the 5 pure ILs is thus much lower than that of water.

Effect of NPs on Thermal Conductivity of ILs. The effect of NPs on thermal conductivity of ILs is investigated. The two samples of $\mathrm{BmimBF}_{4}+\mathrm{Fe}_{2} \mathrm{O}_{3} \mathrm{NPs}$ and $\mathrm{BmimPF}_{6}+\mathrm{R} 711$ NPs are utilized. The curves of temperature increase versus elapsed time are obtained and shown in Fig. 4. The curves of temperature increase versus $\mathrm{D}(\tau)$ are obtained and shown in Fig. 5. Subsequently, the thermal conductivity values of the samples can be calculated. The results are shown in Table 3. As shown in Table 2, the thermal conductivity of $\mathrm{BmimBF}_{4}$ is $0.1898 \mathrm{Wm}^{-1} \mathrm{~K}^{-1}$ at $21{ }^{\circ} \mathrm{C}$. As shown in Table 3 , the thermal conductivity of the $\mathrm{BmimBF}_{4}+\mathrm{Fe}_{2} \mathrm{O}_{3} \mathrm{NPs}$ sample becomes $0.1895 \mathrm{Wm}^{-1} \mathrm{~K}^{-1}$ at $21^{\circ} \mathrm{C}$. Hence, it is shown that the thermal conductivity of $\mathrm{BmimBF}_{4}$ does not change significantly in the presence of $\mathrm{Fe}_{2} \mathrm{O}_{3} \mathrm{NPs}_{\text {. }}$

However, as shown in Table 2, the thermal conductivity of $\mathrm{BmimPF}_{6}$ is $0.1733 \mathrm{Wm}^{-1} \mathrm{~K}^{-1}$ at $21{ }^{\circ} \mathrm{C}$. As shown in Table 3, the thermal conductivity of the $\mathrm{BmimPF}_{6}+\mathrm{R} 711 \mathrm{NPs}$ sample becomes $0.1670 \mathrm{Wm}^{-}$ ${ }^{1} \mathrm{~K}^{-1}$ at $21{ }^{\circ} \mathrm{C}$. Hence, it illustrates that the thermal conductivity of $\mathrm{BmimPF}_{6}$ decreases about $3.6 \%$ in the presence of R711 NPs.

\section{Thermal Diffusivity Measurements}

Pure ILs Thermal Diffusivity Measurements. Thermal diffusivity of pure ILs, including $\mathrm{BmimBF}_{4}$, $\mathrm{BmimPF}_{6}, \mathrm{BmimFeCl}_{4}, \mathrm{OmimCl}$ and $\mathrm{OmimFeCl}_{4}$, is measured. The results are shown in Table 4. The thermal diffusivity values of the ILs are no more than $0.1185 \mathrm{~mm}^{2} \mathrm{~s}^{-1}$. This value is less than the thermal diffusivity of water $0.143 \mathrm{~mm}^{2} \mathrm{~s}^{-1}$ [42]. It illustrates that the ILs also have a better property than water for energy storage. Therefore, ILs may be considered as a type of novel materials for energy storage.

Effect of NPs on Thermal Diffusivity of ILs. The effect of NPs on thermal diffusivity of ILs is investigated. The results are shown in Table 5. Similarly to the effect of NPs on thermal conductivity, the samples of $\mathrm{BmimBF}_{4}+\mathrm{Fe}_{2} \mathrm{O}_{3} \mathrm{NPs}$ and $\mathrm{BmimPF}_{6}+\mathrm{R} 711$ NPs are utilized. As shown in Table 4, the thermal diffusivity of $\mathrm{BmimBF}_{4}$ is $0.1140 \mathrm{~mm}^{2} \mathrm{~s}^{-1}$ at $21^{\circ} \mathrm{C}$. As shown in Table 5 , the thermal diffusivity of the $\mathrm{BmimBF}_{4}+\mathrm{Fe}_{2} \mathrm{O}_{3}$ NPs sample becomes $0.1116 \mathrm{~mm}^{2} \mathrm{~s}^{-1}$ at $21^{\circ} \mathrm{C}$. Hence, it is shown that the thermal diffusivity of $\mathrm{BmimBF}_{4}$ does not change significantly in the presence of $\mathrm{Fe}_{2} \mathrm{O}_{3} \mathrm{NPs}$.

For $\mathrm{BmimPF}_{6}$, as shown in Table 4, the thermal diffusivity is $0.1082 \mathrm{~mm}^{2} \mathrm{~s}^{-1}$ at $21{ }^{\circ} \mathrm{C}$. As shown in Table 5, the thermal conductivity of the $\mathrm{BmimPF}_{6}+\mathrm{R} 711 \mathrm{NPs}$ sample becomes $0.09673 \mathrm{~mm}^{2} \mathrm{~s}^{-1}$ at $21{ }^{\circ} \mathrm{C}$. Hence, the thermal diffusivity of $\mathrm{BmimPF}_{6}$ decreases about $10.6 \%$ in the presence of R711 NPs.

\section{Conclusions}


ILs represent a hot research topic and have thus been utilized in many scientific research fields. For example, ILs may be utilized in energy devices, including solar cells, batteries, and supercapacitors. Thermal conductivity and thermal diffusivity of ILs are crucial for real energy conversion and energy storage processes. However, the thermal conductivity and thermal diffusivity of ILs are often unknown. Therefore, in this work the thermal conductivity and thermal diffusivity of ILs are investigated. A thermal conductivity and thermal diffusivity measurement method for ILs is developed.

Thermal conductivity of pure ILs $\mathrm{BmimBF}_{4}, \mathrm{BmimPF}_{6}, \mathrm{OmimCl}, \mathrm{BmimFeCl}_{4}$ and $\mathrm{OmimFeCl}_{4}$, is measured. It is found that the thermal conductivity of the five pure ILs is much lower than the thermal conductivity of water. The effect of NPs on thermal conductivity of ILs is also investigated. It is shown that the thermal conductivity of $\mathrm{BmimBF}_{4}$ does not change significantly in the presence of $\mathrm{Fe}_{2} \mathrm{O}_{3} \mathrm{NPs}_{\text {. }}$ However, the thermal conductivity of $\mathrm{BmimPF}_{6}$ decreases somewhat in the presence of R711 NPs.

Furthermore, thermal diffusivity of ILs is measured in this work. Thermal diffusivity of 5 pure ILs, including $\mathrm{BmimBF}_{4}, \mathrm{BmimPF}_{6}, \mathrm{BmimFeCl}_{4}, \mathrm{OmimCl}$ and $\mathrm{OmimFeCl}_{4}$, is measured. The thermal diffusivity of the ILs is no more than $0.1185 \mathrm{~mm}^{2} \mathrm{~s}^{-1}$ at $21{ }^{\circ} \mathrm{C}$. The thermal diffusivity of water is 0.143 $\mathrm{mm}^{2} \mathrm{~s}^{-1}$ at $25^{\circ} \mathrm{C}$, which means ILs have a better property than water for energy storage. Therefore, ILs may be considered as a type of novel materials for energy storage. The effect of NPs on the thermal diffusivity of ILs is also investigated. It is shown that the thermal diffusivity of $\mathrm{BmimBF}_{4}$ does not change significantly in the presence of $\mathrm{Fe}_{2} \mathrm{O}_{3} \mathrm{NPs}$. However, the thermal diffusivity of $\mathrm{BmimPF}_{6}$ decreases about $10.6 \%$ in the presence of R711 NPs.

\section{Acknowledgements}

The authors acknowledge UiT The Arctic University of Norway for financial support. 


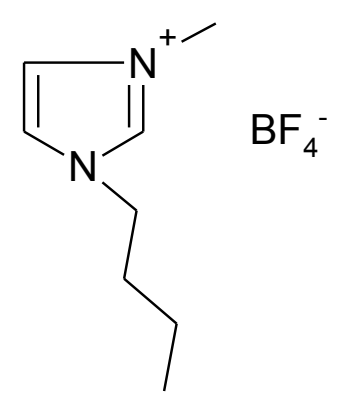

(a)

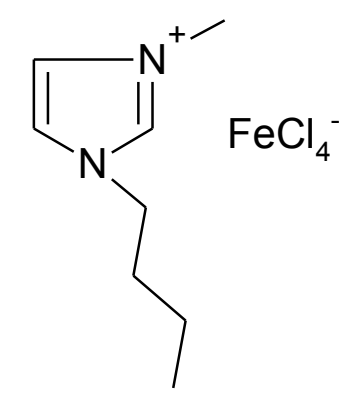

(d)

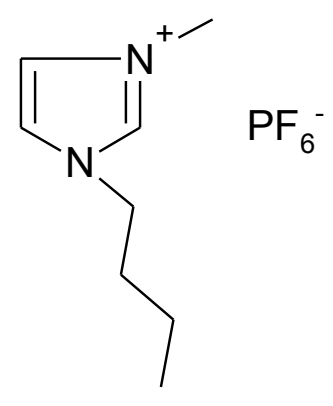

(b)

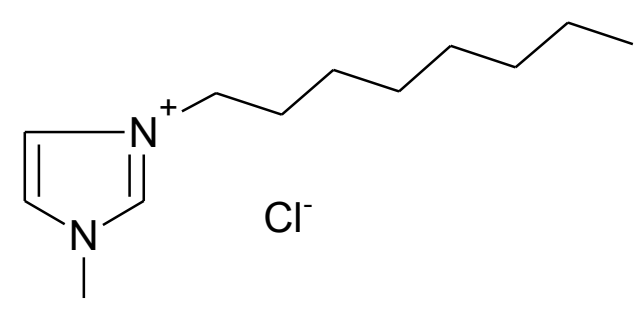

(c)

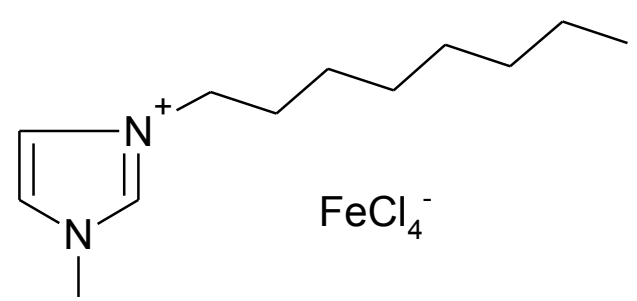

(e)

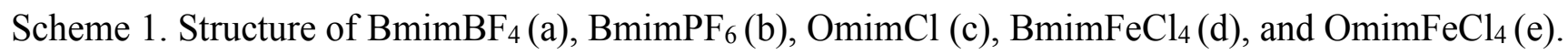


Table 1 . Thermal conductivity of water at $21^{\circ} \mathrm{C}$.

\begin{tabular}{|c|c|c|c|}
\hline Water & Experiment number & Test value $/ \mathrm{Wm}^{-1} \mathrm{~K}^{-1}$ & Average value $/ \mathrm{Wm}^{-1} \mathrm{~K}^{-1}$ \\
\hline & 1 & 0.6080 & \\
\hline & 2 & 0.6022 & \\
\hline & 3 & 0.6147 & \\
\hline & 4 & 0.6010 & \\
\hline & 5 & 0.5906 & \\
\hline & & & 0.6033 \\
\hline
\end{tabular}


Table 2. Thermal conductivity of $\mathrm{BmimBF}_{4}, \mathrm{BmimPF}_{6}, \mathrm{OmimCl}, \mathrm{BmimFeCl}_{4}$ and $\mathrm{OmimFeCl}_{4}$ at $21{ }^{\circ} \mathrm{C}$.

\begin{tabular}{|c|c|c|c|}
\hline Sample & Experiment number & Test value $/ \mathrm{Wm}^{-1} \mathrm{~K}^{-1}$ & Average value $/ \mathrm{Wm}^{-1} \mathrm{~K}^{-1}$ \\
\hline \multirow[t]{5}{*}{$\mathrm{BmimBF}_{4}$} & 1 & 0.1900 & \\
\hline & 2 & 0.1891 & \\
\hline & 3 & 0.1890 & \\
\hline & 4 & 0.1909 & \\
\hline & & & 0.1898 \\
\hline \multirow[t]{4}{*}{$\mathrm{BmimPF}_{6}$} & 1 & 0.1738 & \\
\hline & 2 & 0.1709 & \\
\hline & 3 & 0.1753 & \\
\hline & & & 0.1733 \\
\hline \multirow[t]{5}{*}{$\mathrm{OmimCl}$} & 1 & 0.1881 & \\
\hline & 2 & 0.1862 & \\
\hline & 3 & 0.1918 & \\
\hline & 4 & 0.1829 & \\
\hline & & & 0.1873 \\
\hline \multirow[t]{5}{*}{$\mathrm{BmimFeCl}_{4}$} & 1 & 0.1671 & \\
\hline & 2 & 0.1692 & \\
\hline & 3 & 0.1703 & \\
\hline & 4 & 0.1655 & \\
\hline & & & 0.1680 \\
\hline $\mathrm{OmimFeCl}_{4}$ & 1 & 0.1692 & \\
\hline
\end{tabular}


0.1692

3

0.1642

4

0.1596

0.1656 
Table 3. Thermal conductivity of samples of $\mathrm{BmimBF}_{4}+\mathrm{Fe}_{2} \mathrm{O}_{3} \mathrm{NPs}$ and $\mathrm{BmimPF}_{6}+\mathrm{R} 711$ NPs at 21 ${ }^{\circ} \mathrm{C}$.

\begin{tabular}{llll}
\hline Sample & Experiment number & Test value $/ \mathrm{Wm}^{-1} \mathrm{~K}^{-1}$ & Average value $/ \mathrm{Wm}^{-1} \mathrm{~K}^{-1}$ \\
\hline $\mathrm{BmimBF}_{4}+\mathrm{Fe}_{2} \mathrm{O}_{3} \mathrm{NPs}$ & 1 & 0.1892 & \\
& 2 & 0.1890 & \\
& 3 & 0.1864 & \\
& 4 & 0.1934 & 0.1895 \\
$\mathrm{BmimPF}_{6}+\mathrm{R} 711 \mathrm{NPs}$ & 1 & & \\
& 2 & 0.1685 & \\
& 3 & 0.1670 & \\
& & 0.1645 & 0.1670 \\
& & 0.1678 & \\
\hline
\end{tabular}


Table 4. Thermal diffusivity of $\mathrm{BmimBF}_{4}, \mathrm{BmimPF}_{6}, \mathrm{OmimCl}, \mathrm{BmimFeCl}_{4}$ and $\mathrm{OmimFeCl}_{4}$ at $21^{\circ} \mathrm{C}$.

\begin{tabular}{|c|c|c|c|}
\hline Sample & Experiment number & Test value $/ \mathrm{mm}^{2} \mathrm{~s}^{-1}$ & Average value $/ \mathrm{mm}^{2} \mathrm{~s}^{-1}$ \\
\hline \multirow[t]{5}{*}{$\mathrm{BmimBF}_{4}$} & 1 & 0.1142 & \\
\hline & 2 & 0.1141 & \\
\hline & 3 & 0.1126 & \\
\hline & 4 & 0.1151 & \\
\hline & & & 0.1140 \\
\hline \multirow[t]{4}{*}{$\mathrm{BmimPF}_{6}$} & 1 & 0.1096 & \\
\hline & 2 & 0.1041 & \\
\hline & 3 & 0.1109 & \\
\hline & & & 0.1082 \\
\hline \multirow[t]{5}{*}{ OmimCl } & 1 & 0.1105 & \\
\hline & 2 & 0.1055 & \\
\hline & 3 & 0.1149 & \\
\hline & 4 & 0.1000 & \\
\hline & & & 0.1077 \\
\hline \multirow[t]{5}{*}{$\mathrm{BmimFeCl}_{4}$} & 1 & 0.1174 & \\
\hline & 2 & 0.1208 & \\
\hline & 3 & 0.1229 & \\
\hline & 4 & 0.1129 & \\
\hline & & & 0.1185 \\
\hline $\mathrm{OmimFeCl}_{4}$ & 1 & 0.1140 & \\
\hline
\end{tabular}


0.1085

4

0.1017

0.1105 
Table 5. Thermal diffusivity of samples of $\mathrm{BmimBF}_{4}+\mathrm{Fe}_{2} \mathrm{O}_{3} \mathrm{NPs}$ and $\mathrm{BmimPF}_{6}+\mathrm{R} 711 \mathrm{NPs}$ at $21^{\circ} \mathrm{C}$.

\begin{tabular}{|c|c|c|c|}
\hline Sample & Experiment number & Test value $/ \mathrm{mm}^{2} \mathrm{~s}^{-1}$ & Average value $/ \mathrm{mm}^{2} \mathrm{~s}^{-1}$ \\
\hline \multirow[t]{5}{*}{$\mathrm{BmimBF}_{4}+\mathrm{Fe}_{2} \mathrm{O}_{3} \mathrm{NPs}$} & 1 & 0.1111 & \\
\hline & 2 & 0.1106 & \\
\hline & 3 & 0.1062 & \\
\hline & 4 & 0.1183 & \\
\hline & & & 0.1116 \\
\hline \multirow[t]{5}{*}{$\mathrm{BmimPF}_{6}+\mathrm{R} 711 \mathrm{NPs}$} & 1 & 0.09929 & \\
\hline & 2 & 0.09635 & \\
\hline & 3 & 0.09298 & \\
\hline & 4 & 0.09829 & \\
\hline & & & 0.09673 \\
\hline
\end{tabular}




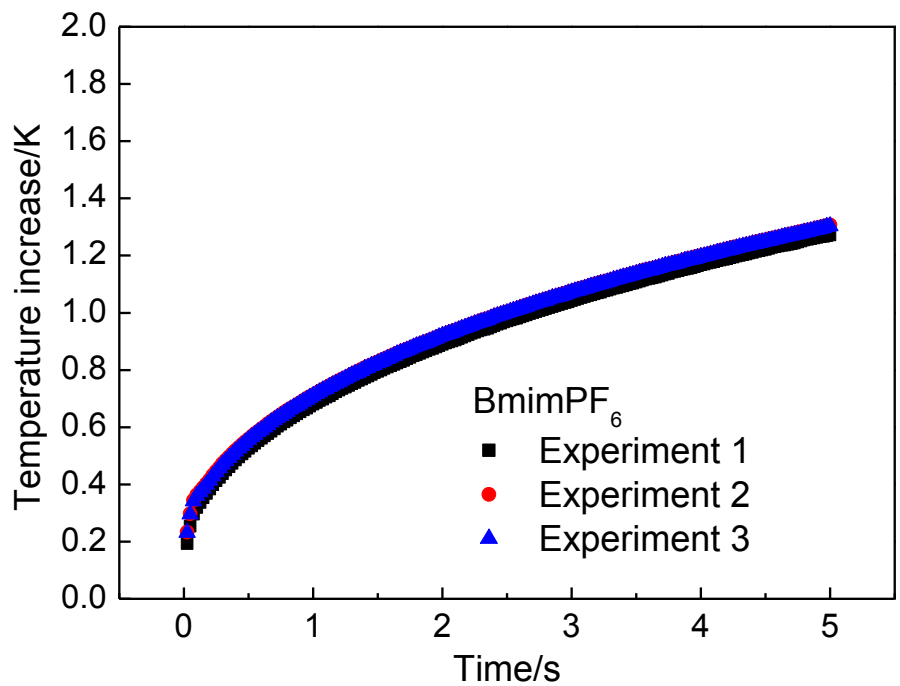

(a)

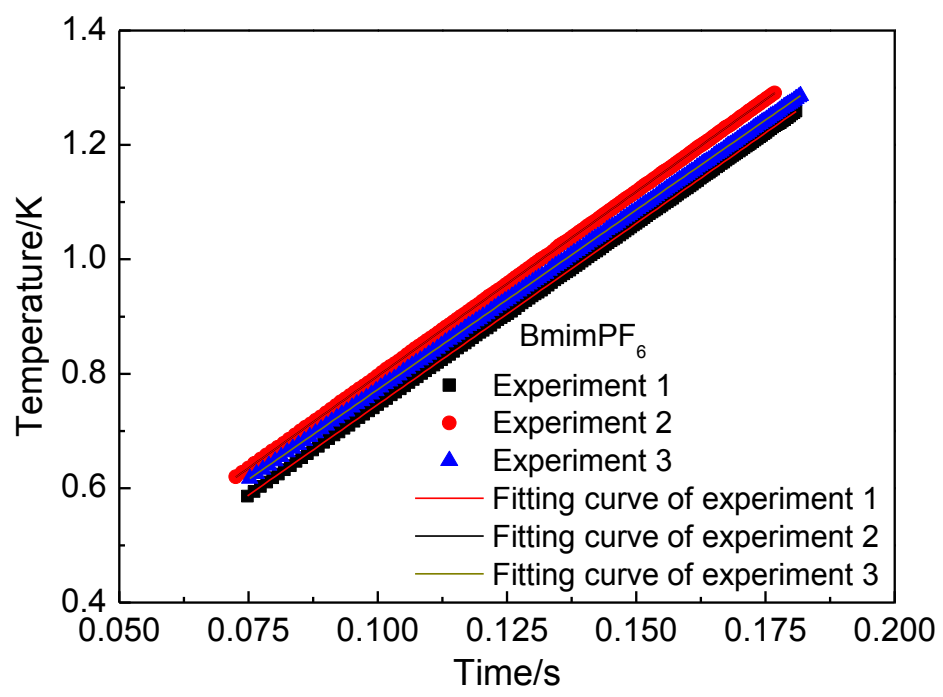

(b) 


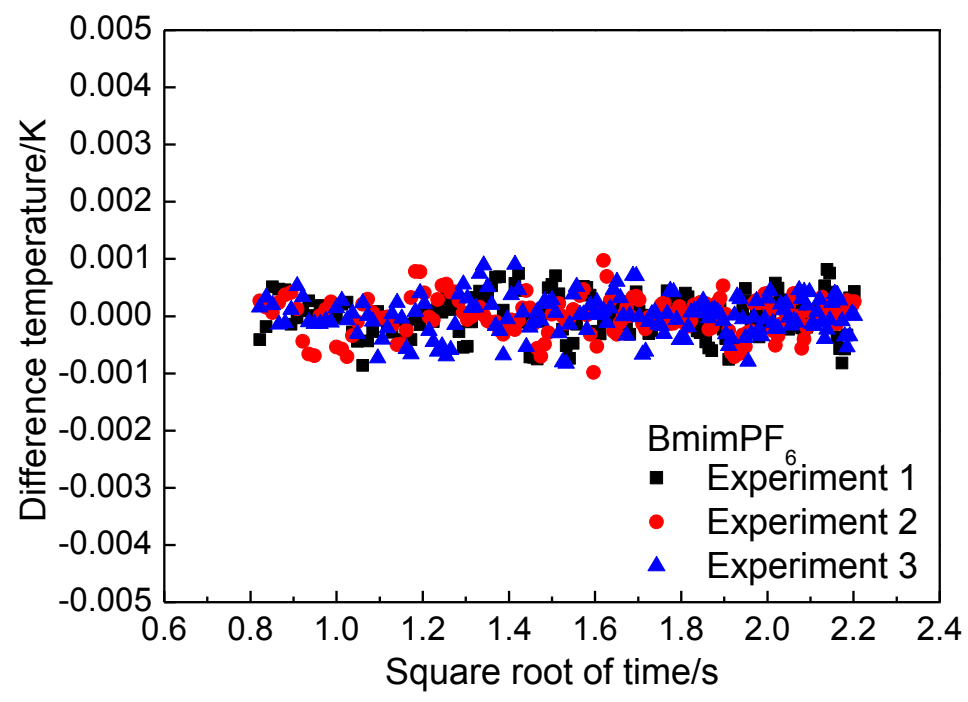

(c)

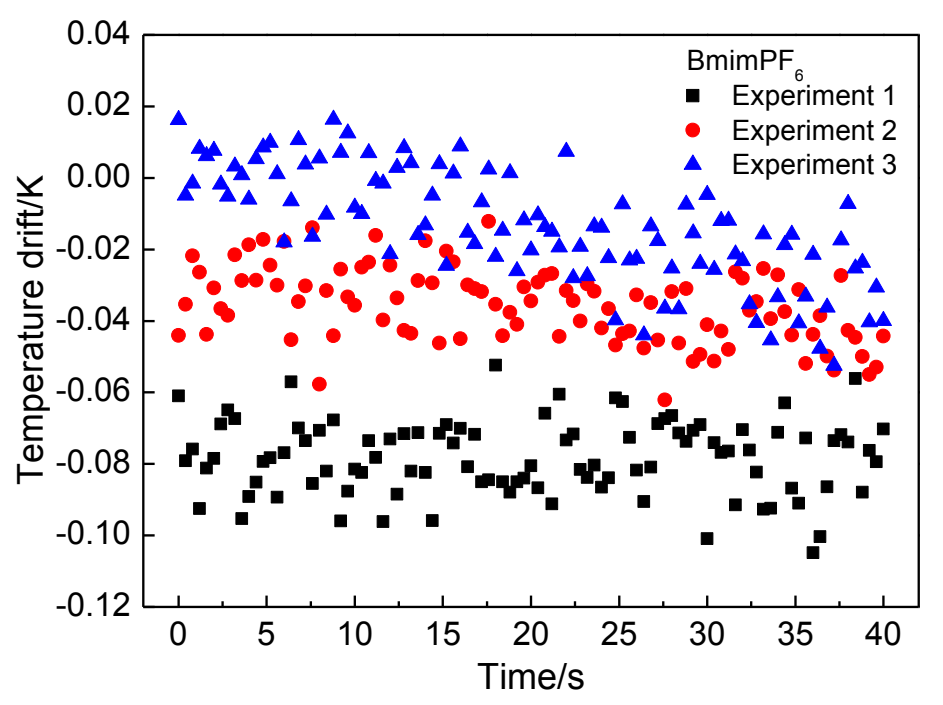

(d)

Fig. 1. Thermal conductivity and thermal diffusivity measurement of BmimPF 6 . (a) Temperature increase versus time; (b) Temperature increase versus $D(\tau)$. (The slopes of the fitting curves of experiments 1, 2 and 3 are $6.3337,6.4415,6.2822$, respectively. The $\mathrm{R}^{2}$ of all the fitting curves of experiments 1,2 and 3 are 1). (c) Difference temperature versus square root of time; (d) Temperature drift versus time. 


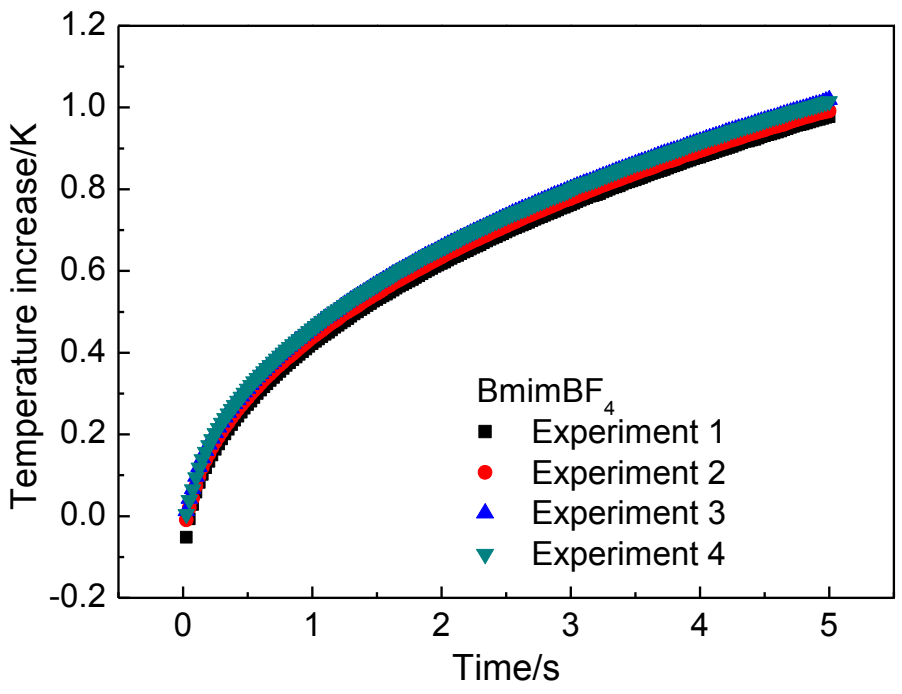

(a)

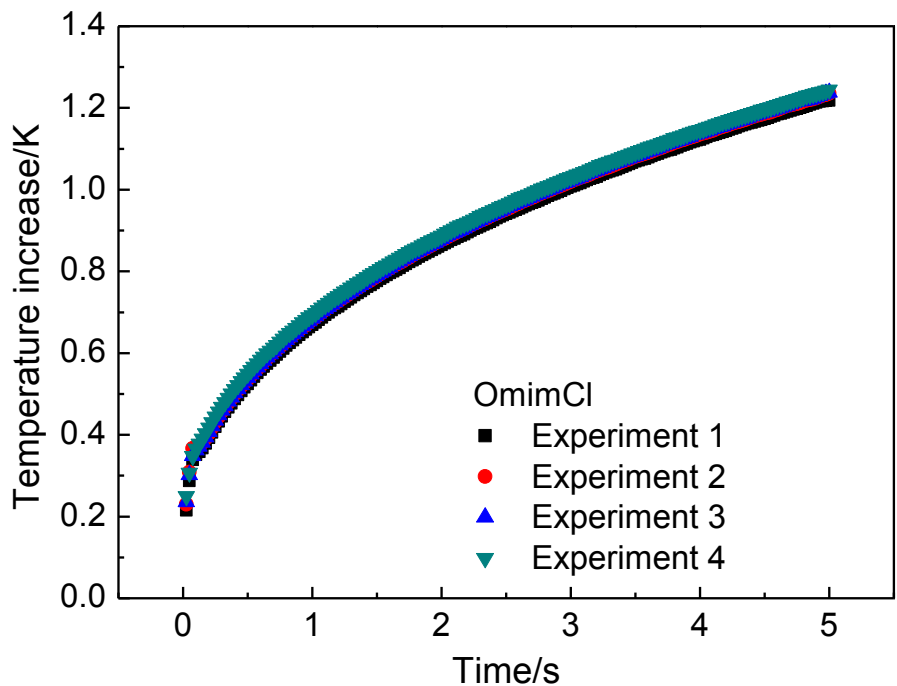

(b) 


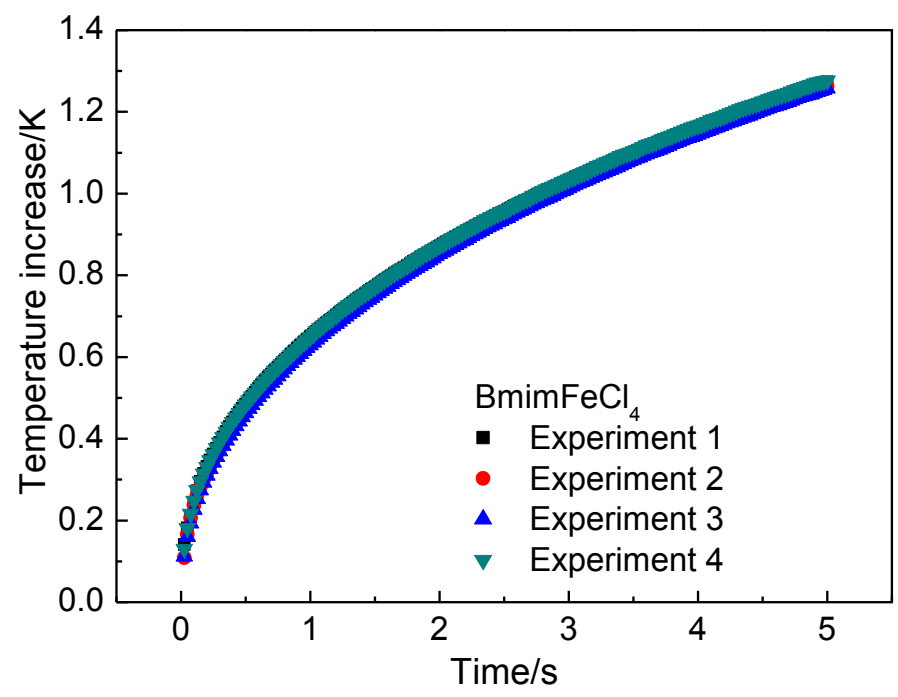

(c)

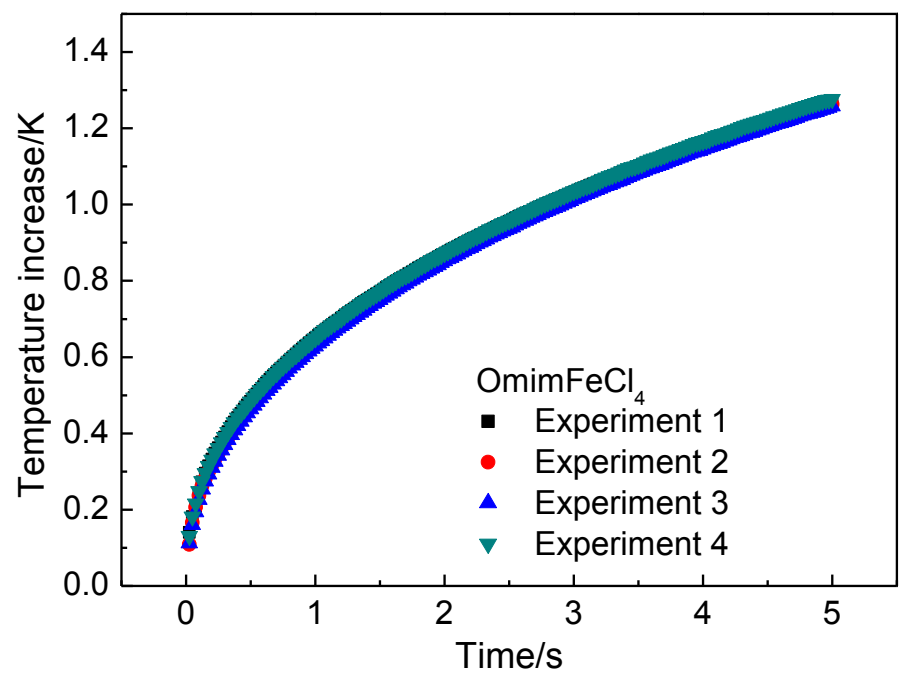

(d)

Fig. 2. Temperature increase versus time during the measurement process in $\mathrm{BmimBF}_{4}, \mathrm{OmimCl}_{\text {, }}$ $\mathrm{BmimFeCl}_{4}$ and $\mathrm{OmimFeCl}_{4}$. 


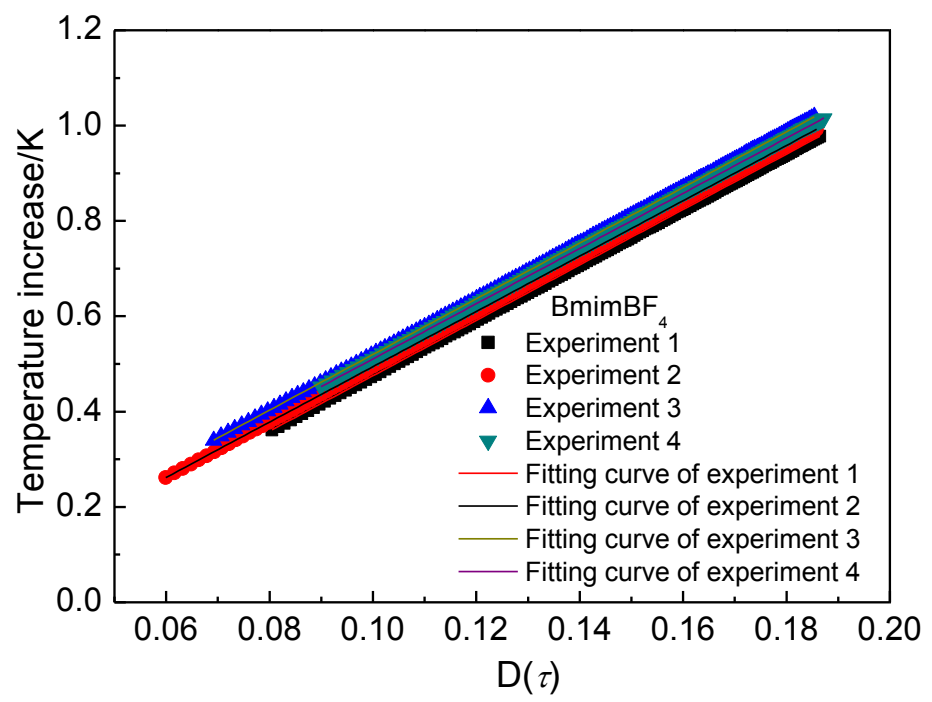

(a)

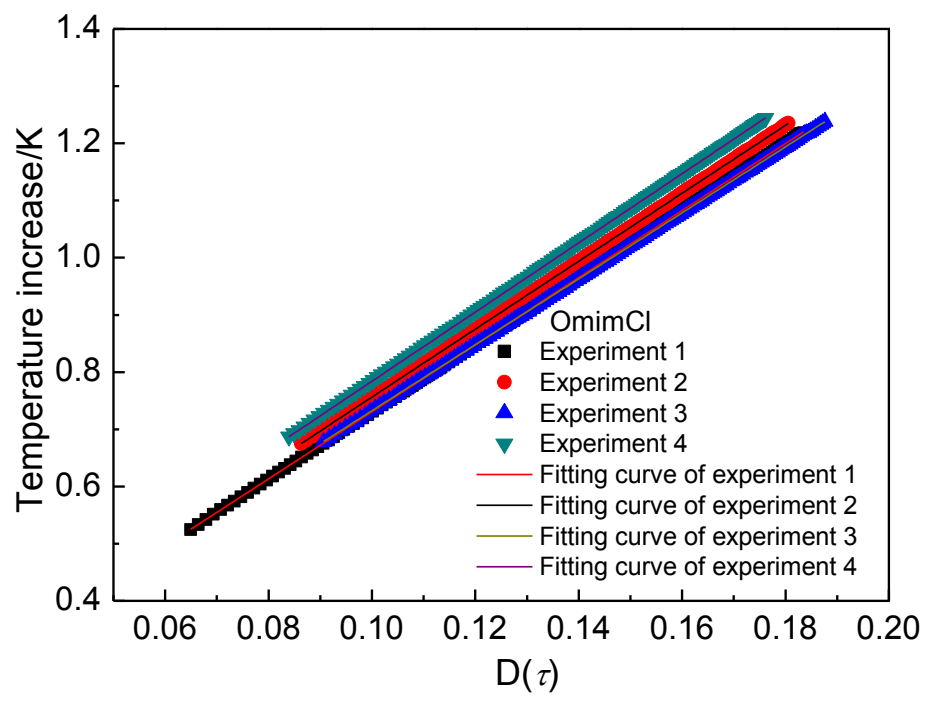

(b) 


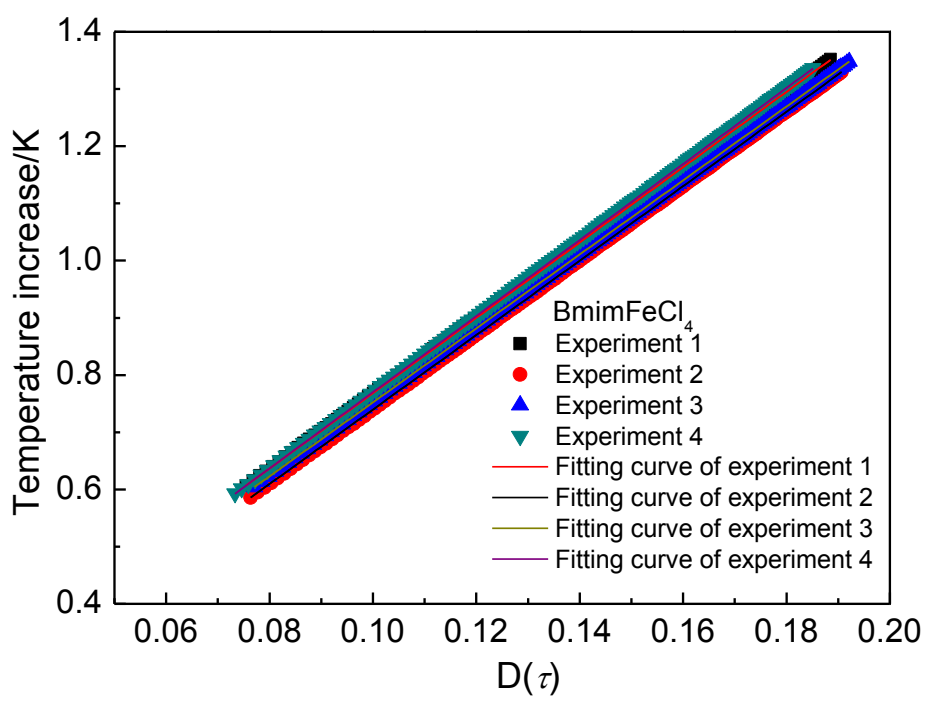

(c)

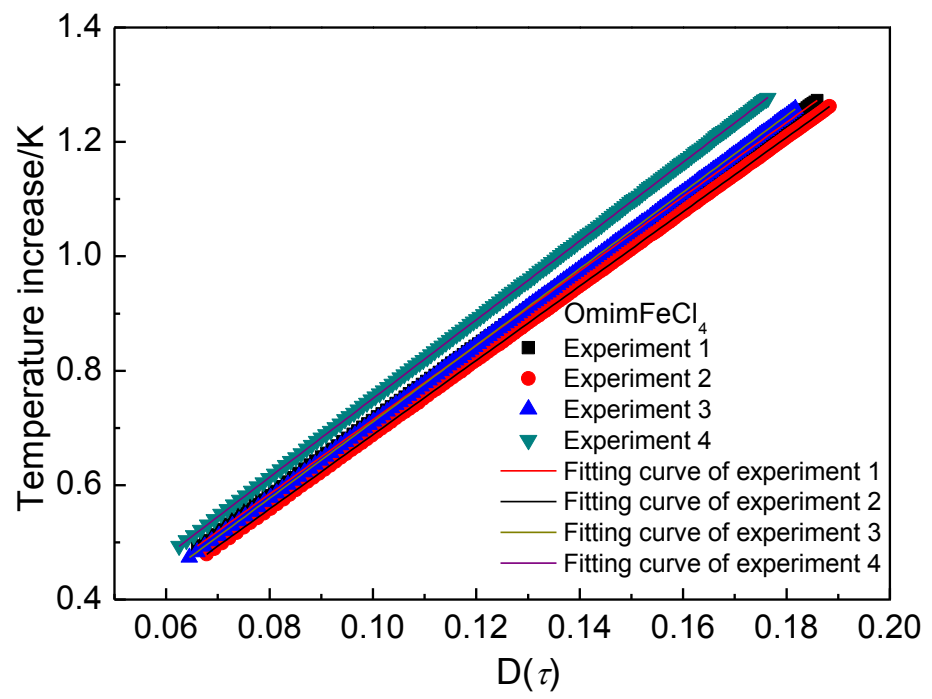

(d)

Fig. 3. Temperature increase versus $\mathrm{D}(\tau)$ curves and the linear fitting lines of temperature increase versus $\mathrm{D}(\tau)$ in $\mathrm{BmimBF}_{4}$ (a, The slopes of the fitting curves of experiments 1, 2, 3 and 4 are 5.8127, 5.8035, $5.8376,5.7915$, respectively. The $\mathrm{R}^{2}$ of all the fitting curves of experiments $1,2,3$, and 4 are 1). OmimCl (b, The slopes of the fitting curves of experiments 1, 2, 3 and 4 are 5.8625, 5.9399, 5.7662, 6.0480, respectively. The $R^{2}$ of all the fitting curves of experiments $1,2,3$, and 4 are 1 ), $\mathrm{BmimFeCl}_{4}$ (c, The slopes of the fitting curves of experiments $1,2,3$ and 4 are $6.5846,6.5063,6.4654,6.6489$, respectively. The $\mathrm{R}^{2}$ of all the fitting curves of experiments $1,2,3$, and 4 are 1) and $\mathrm{OmimFeCl}_{4}$ (d, The slopes of the fitting curves of experiments $1,2,3$ and 4 are $6.4980,6.4942,6.6907,6.8855$, respectively. The $\mathrm{R}^{2}$ of all the fitting curves of experiments $1,2,3$, and 4 are 1). 


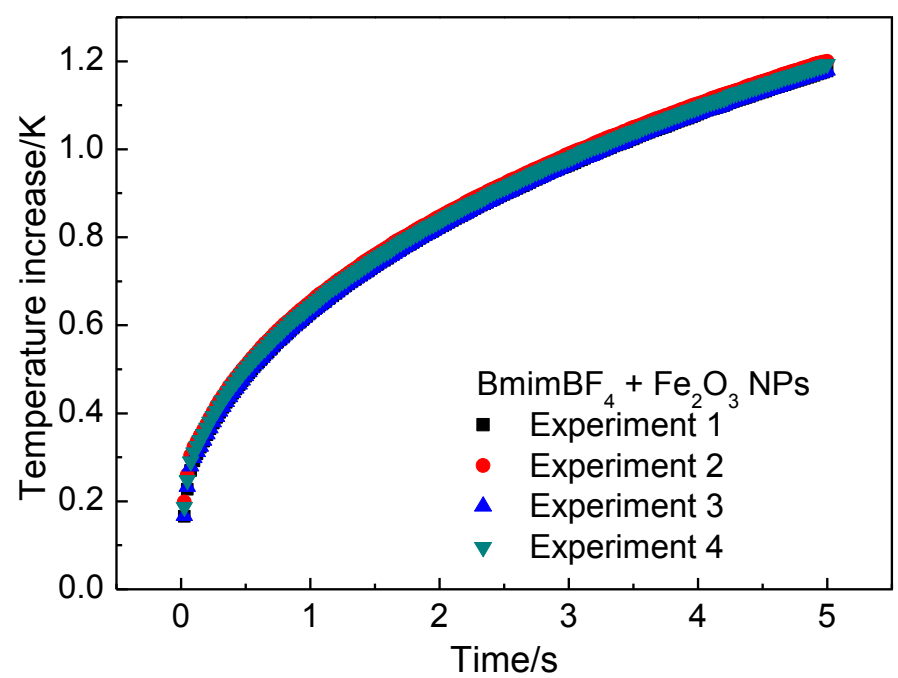

(a)

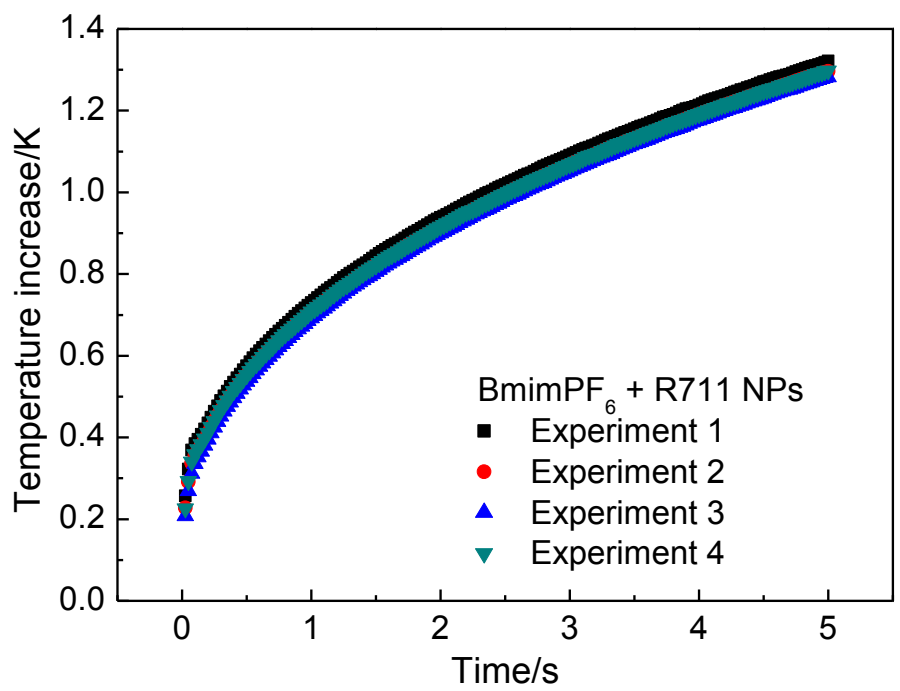

(b)

Fig. 4. Temperature increase versus time during the measurement process in $\mathrm{BmimBF}_{4}+\mathrm{Fe}_{2} \mathrm{O}_{3} \mathrm{NPs}_{\mathrm{s}}$ and BmimPF $_{6}+$ R711 NPs samples. 


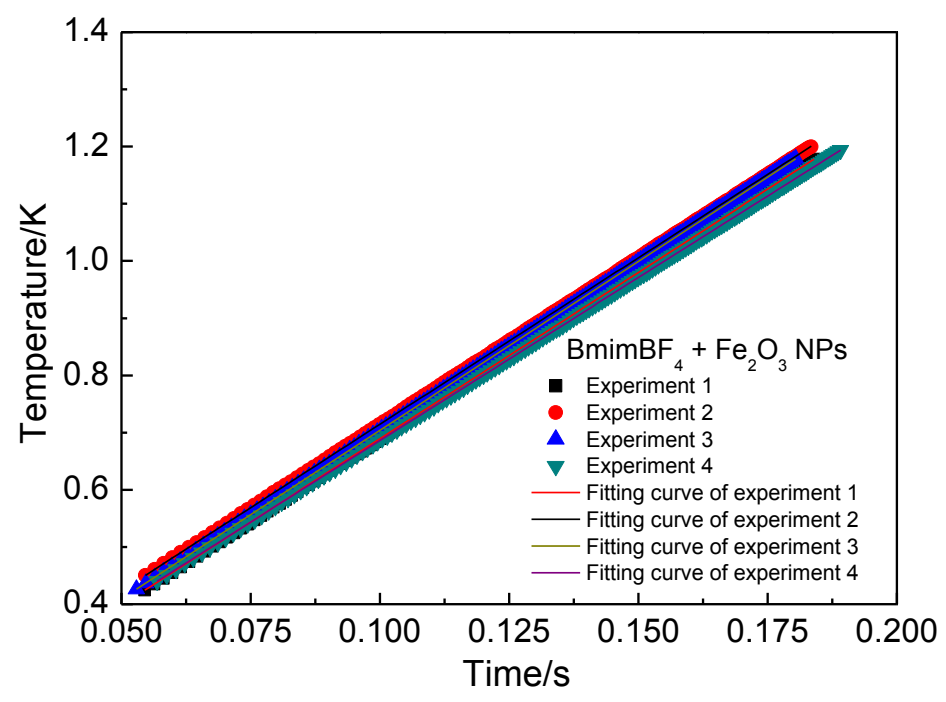

(a)

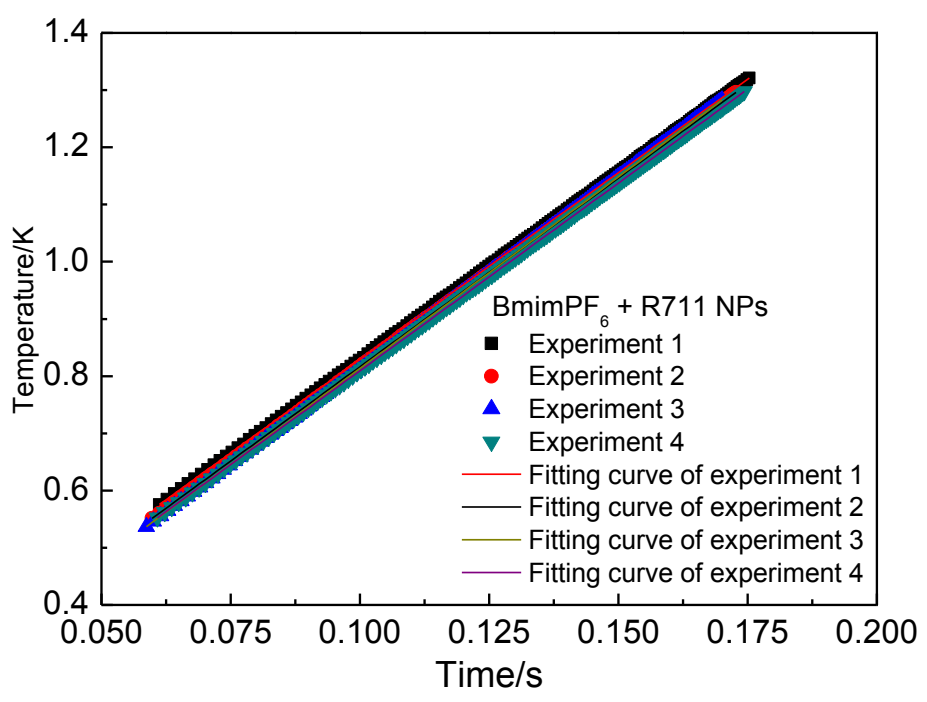

(b)

Fig. 5. Temperature increase versus $\mathrm{D}(\tau)$ curves and the linear fitting lines of temperature increase versus $\mathrm{D}(\tau)$ in the sample of $\mathrm{BmimBF}_{4}+\mathrm{Fe}_{2} \mathrm{O}_{3} \mathrm{NPs}$ (a, The slopes of the fitting curves of experiments $1,2,3$ and 4 are 5.8176, 5.8230, 5.9036, 5.6990, respectively. The $\mathrm{R}^{2}$ of all the fitting curves of experiments $1,2,3$, and 4 are 1) and $\mathrm{BmimPF}_{6}+\mathrm{R} 711 \mathrm{NPs}(\mathrm{b}$, The slopes of the fitting curves of experiments 1, 2, 3 and 4 are $6.5338,6.5939,6.6943,6.5609$, respectively. The $\mathrm{R}^{2}$ of all the fitting curves of experiments $1,2,3$, and 4 are 1 ). 


\section{References}

1. Bidikoudi M, Perganti D, Karagianni C-S, Falaras P. Solidification of ionic liquid redox electrolytes using agarose biopolymer for highly performing dye-sensitized solar cells. Electrochimica Acta. 2015; 179: 228-236.

2. Erten-Ela S, Ocakoglu K. Iridium dimer complex for dye sensitized solar cells using electrolyte combinations with different ionic liquids. Materials Science in Semiconductor Processing. 2014; 27: $532-540$.

3. Hashmi SG, Ozkan M, Halme J, Misic KD, Zakeeruddin SM, Paltakari J, Grätzel M, Lund PD. High performance dye-sensitized solar cells with inkjet printed ionic liquid electrolyte. Nano Energy. 2015; 17: 206-215.

4. Khanmirzaei MH, Ramesh S, Ramesh K. Polymer electrolyte based dye-sensitized solar cell with rice starch and 1-methyl-3-propylimidazolium iodide ionic liquid. Materials \& Design. 2015; 85: 833837.

5. Lin B, Shang H, Chu F, Ren Y, Yuan N, Jia B, Zhang S, Yu X, Wei Y, Ding J. Ionic liquid-tethered Graphene Oxide/Ionic Liquid Electrolytes for Highly Efficient Dye Sensitized Solar Cells. Electrochimica Acta. 2014; 134: 209-214.

6. Ng HM, Ramesh S, Ramesh K. Efficiency improvement by incorporating 1-methyl-3propylimidazolium iodide ionic liquid in gel polymer electrolytes for dye-sensitized solar cells. Electrochimica Acta. 2015; 175: 169-175.

7. Apostolopoulou A, Nagygyörgy V, Madarász J, Stathatos E, Pokol G. Thermal stability and electrical studies on hybrid and composite sol-gel quasi-solid-state electrolytes for dye-sensitized solar cells. Journal of Thermal Analysis and Calorimetry. 2015; 121: 371-380.

8. Ding C, Nohira T, Hagiwara R, Matsumoto K, Okamoto Y, Fukunaga A, Sakai S, Nitta K, Inazawa S. $\mathrm{Na}[\mathrm{FSA}]-[\mathrm{C} 3 \mathrm{C} 1$ pyrr][FSA] ionic liquids as electrolytes for sodium secondary batteries: Effects of $\mathrm{Na}$ ion concentration and operation temperature. Journal of Power Sources. 2014; 269: 124128.

9. Ejigu A, Greatorex-Davies PA, Walsh DA. Room temperature ionic liquid electrolytes for redox flow batteries. Electrochemistry Communications. 2015; 54: 55-59.

10. Guisao JPT, Romero AJF. Interaction between $\mathrm{Zn} 2+$ cations and n-methyl-2-pyrrolidone in ionic liquid-based Gel Polymer Electrolytes for Zn batteries. Electrochimica Acta. 2015; 176: 1447 1453.

11. He X, Wang J, Jia H, Kloepsch R, Liu H, Beltrop K, Li J. Ionic liquid-assisted solvothermal synthesis of hollow Mn2O3 anode and LiMn2O4 cathode materials for Li-ion batteries. Journal of Power Sources. 2015; 293: 306-311. 
12. Hofmann A, Schulz M, Indris S, Heinzmann R, Hanemann T. Mixtures of Ionic Liquid and Sulfolane as Electrolytes for Li-Ion Batteries. Electrochimica Acta. 2014; 147: 704-711.

13. Jiang M, Wang X, Shen Y, Hu H, Fu Y, Yang X. New iron-based fluoride cathode material synthesized by non-aqueous ionic liquid for rechargeable sodium ion batteries. Electrochimica Acta. 2015; 186: 7-15.

14. Krummacher J, Passerini S, Balducci A. Ionic liquid assisted solid-state synthesis of lithium iron oxide nanoparticles for rechargeable lithium ion batteries. Solid State Ionics. 2015; 280: 37-43.

15. Kuo P-L, Tsao C-H, Hsu C-H, Chen S-T, Hsu H-M. A new strategy for preparing oligomeric ionic liquid gel polymer electrolytes for high-performance and nonflammable lithium ion batteries. Journal of Membrane Science. 2016; 499: 462-469.

16. Wu F, Zhu Q, Chen R, Chen N, Chen Y, Ye Y, Qian J, Li L. Ionic liquid-based electrolyte with binary lithium salts for high performance lithium-sulfur batteries. Journal of Power Sources. 2015; 296: $10-17$.

17. Arbizzani C, Beninati S, Lazzari M, Soavi F, Mastragostino M. Electrode materials for ionic liquidbased supercapacitors. Journal of Power Sources. 2007; 174: 648-652.

18. Awale DV, Bhise SC, Patil SK, Vadiyar MM, Jadhav PR, Navathe GJ, Kim JH, Patil PS, Kolekar SS. Nanopetals assembled copper oxide electrode for supercapacitor using novel 1-(1' -methyl$2^{\prime}$-oxo-propyl)-2,3-dimethylimidazolium chloride ionic liquid as an electrolyte. Ceramics International. 2016; 42: 2699-2705.

19. Balducci A, Bardi U, Caporali S, Mastragostino M, Soavi F. Ionic liquids for hybrid supercapacitors. Electrochemistry Communications. 2004; 6: 566-570.

20. Huang P-L, Luo X-F, Peng Y-Y, Pu N-W, Ger M-D, Yang C-H, Wu T-Y, Chang J-K. Ionic Liquid Electrolytes with Various Constituent Ions for Graphene-based Supercapacitors. Electrochimica Acta. 2015; 161: 371-377.

21. Maiti S, Pramanik A, Chattopadhyay S, De G, Mahanty S. Electrochemical energy storage in montmorillonite K10 clay based composite as supercapacitor using ionic liquid electrolyte. Journal of Colloid and Interface Science. 2016; 464: 73-82.

22. Pandey GP, Hashmi SA. Performance of solid-state supercapacitors with ionic liquid 1-ethyl-3methylimidazolium tris(pentafluoroethyl) trifluorophosphate based gel polymer electrolyte and modified MWCNT electrodes. Electrochimica Acta. 2013; 105: 333-341.

23. Sathyamoorthi S, Suryanarayanan V, Velayutham D. Organo-redox shuttle promoted protic ionic liquid electrolyte for supercapacitor. Journal of Power Sources. 2015; 274: 1135-1139.

24. Shao Q, Tang J, Lin Y, Li J, Qin F, Zhang K, Yuan J, Qin L-C. Ionic liquid modified graphene for supercapacitors with high rate capability. Electrochimica Acta. 2015; 176: 1441-1446. 
25. Timperman L, Galiano H, Lemordant D, Anouti M. Phosphonium-based protic ionic liquid as electrolyte for carbon-based supercapacitors. Electrochemistry Communications. 2011; 13: 11121115.

26. Wei D, Ng TW. Application of novel room temperature ionic liquids in flexible supercapacitors. Electrochemistry Communications. 2009; 11: 1996-1999.

27. Yang L, Hu J, Lei G, Liu H. Ionic liquid-gelled polyvinylidene fluoride/polyvinyl acetate polymer electrolyte for solid supercapacitor. Chemical Engineering Journal. 2014; 258: 320-326.

28. Zheng C, Qian W, Yu Y, Wei F. Ionic liquid coated single-walled carbon nanotube buckypaper as supercapacitor electrode. Particuology. 2013; 11: 409-414.

29. Feng W-q, Lu Y-h, Chen Y, Lu Y-w, Yang T. Thermal stability of imidazolium-based ionic liquids investigated by TG and FTIR techniques. Journal of Thermal Analysis and Calorimetry. 2016; 125: $143-154$.

30. Jagadeeswara Rao C, Venkata Krishnan R, Venkatesan KA, Nagarajan K, Srinivasan TG. Thermochemical properties of some bis(trifluoromethyl-sulfonyl)imide based room temperature ionic liquids. Journal of Thermal Analysis and Calorimetry. 2009; 97: 937-943.

31. Sattari M, Gharagheizi F, Ilani-Kashkouli P, Mohammadi AH, Ramjugernath D. Development of a group contribution method for the estimation of heat capacities of ionic liquids. Journal of Thermal Analysis and Calorimetry. 2014; 115: 1863-1882.

32. Albert J, Müller K. Thermal conductivity of Ionic Liquids: An estimation approach. Chemical Engineering Science. 2014; 119: 109-113.

33. Lazzús JA. A group contribution method to predict the thermal conductivity $\lambda(\mathrm{T}, \mathrm{P})$ of ionic liquids. Fluid Phase Equilibria. 2015; 405: 141-149.

34. Lazzús JA, Pulgar-Villarroel G. Estimation of thermal conductivity of ionic liquids using quantitative structure-property relationship calculations. Journal of Molecular Liquids. 2015; 211: 981-985.

35. Frez C, Diebold GJ, Tran CD, Yu S. Determination of Thermal Diffusivities, Thermal Conductivities, and Sound Speeds of Room-Temperature Ionic Liquids by the Transient Grating Technique. Journal of Chemical \& Engineering Data. 2006; 51: 1250-1255.

36. Ge R, Hardacre C, Nancarrow P, Rooney DW. Thermal Conductivities of Ionic Liquids over the Temperature Range from 293 K to 353 K. Journal of Chemical \& Engineering Data. 2007; 52: 1819-1823.

37. Fröba AP, Rausch MH, Krzeminski K, Assenbaum D, Wasserscheid P, Leipertz A. Thermal Conductivity of Ionic Liquids: Measurement and Prediction. International Journal of Thermophysics. 2010; 31: 2059-2077. 
38. Verevkin SP, Emel'yanenko VN, Zaitsau DH, Ralys RV, Schick C. Ionic Liquids: Differential Scanning Calorimetry as a New Indirect Method for Determination of Vaporization Enthalpies. Journal of Physical Chemistry B. 2012; 116: 4276-4285.

39. Bodirlau R, Teaca C-A, Spiridon I. Influence of ionic liquid on hydrolyzed cellulose material: FT-IR spectroscopy and TG-DTG-DSC analysis. International Journal of Polymer Analysis and Characterization. 2010; 15: 460-469.

40. Yansong Zhao JHH, and Tobias Boström . Extraction of Magnetic Nanoparticles Using Magnetic Ionic Liquids. Micro \& Nano Letters. 2016; 11(5): 244 - 247.

41. Shojaee SA, Farzam S, Hezave AZ, Lashkarbolooki M, Ayatollahi S. A new correlation for estimating thermal conductivity of pure ionic liquids. Fluid Phase Equilibria. 2013; 354: 199-206. 